\title{
Effects of a New Filling Technique on the Mechanical Properties of ABS Specimens Manufactured by Fused Deposition Modeling
}

Heba Hussam ( $\boldsymbol{\sim}$ heba.hussam@eng.au.edu.eg)

Assiut University Faculty of Engineering

Yasser Abdelrhman

Mohamed Emad S. Soliman

Ibrahim M. Hassab-Allah

\section{Research Article}

Keywords: mechanical properties, FDM, epoxy resin, filling, voiding, injection

Posted Date: February 1st, 2022

DOI: https://doi.org/10.21203/rs.3.rs-1297180/v1

License: (c) (1) This work is licensed under a Creative Commons Attribution 4.0 International License. Read Full License

Version of Record: A version of this preprint was published at The International Journal of Advanced Manufacturing Technology on June 1st, 2022. See the published version at https://doi.org/10.1007/s00170-022-09351-5. 


\section{Abstract}

No one can deny the widespread of 3D printing in many different fields. This paper aims to improve the mechanical properties of parts printed by fused deposition modeling (FDM) technique. Acrylonitrile butadiene styrene (ABS) specimens are printed with custom printing parameters, these parameters give a tensile strength that is $86 \%$ of the injection molded $A B S$ strength, and give one of the best results recorded for $100 \%$ infill printed ABS tensile specimens. Furthermore, a post filling technique has been studied, specimens are printed with inner voids and different densities using slicing software. Void shape is precisely selected to conform to the filling process. High-strength low-cost thermoset resin is injected through specimens to fill these voids. A tensile test has been performed after full curing of the resin and a morphology analysis is done. By this technique strength to printed weight ratio is improved by $151 \%$ and the cost is reduced by $51 \%$.

\section{Introduction}

Additive Manufacturing (AM) is the best choice to fulfill the fourth industrial revolution, as it delivers complex and customized products with great freedom in design in a very short time, reducing the production cost and shortening the development cycle[1]. Stereo-lithography (SLA) is the first technique that AM had started with, which is a liquid-based raw material technique. Later on, many techniques had been invented varying in the raw material from liquid to powder and solid[2]. All AM techniques use threedimensional computer-aided designs (CAD) to produce -layer by layer- three-dimensional products by selectively adding materials, with variety in the materials being used. FDM, solid-based AM technique, is the most common and widely used technique due to its simplicity and modesty in price as it utilizes lowcost polymers only[2, 3]. FDM feeds thermoplastic filament into a heating chamber until it reaches a semi-liquid state, extrudes it through a nozzle above its melting point, then depositing it on the printing platform in specified positions according to the G-code generated by the machine's software[4]. FDM printed parts have been in use in many fields like rapid prototyping, building, healthcare devices and tools, motor drives, and aerospace components[5]. But due to the nature of the FDM technique, it experiences some drawbacks; one of them is the limitation in mechanical properties. This limitation is due to the weak and non-homogenous bonding between the corresponding layers building up the part and also between the roads building the layer itself. Also since the cooling and heating rates in the FDM process are unstable there would be uncontrolled shrink and defects in the microstructure[2, 6].

Many studies had been performed to overcome the pre-mentioned problems, covering different materials that are currently used in FDM (ABS, PLA, PA, NYLON, etc.). Many studies have considered printing parameters as important indices for product quality. They studied the influence of printing orientation, speed, raster angle, infill pattern, nozzle temperature and layer height on the mechanical properties of the printed parts $[7,8]$. Table 1 , summaries the studies done by researchers on 3D printed ABS parts applying different printing parameters. 
Previous work on ABS printed specimens

Authors Parameters and (levels) Outputs

Samykano Printing speed $(30 \mathrm{~mm} / \mathrm{s})$, printing temperature $\left(220^{\circ} \mathrm{C}\right)$, bed

et al. [9] temperature $\left(110^{\circ} \mathrm{C}\right)$, infill pattern (lines), layer height $(0.35,0.4$, and 0.5

$\mathrm{mm})$ and raster angle $\left(45^{\circ}, 55^{\circ}, 65^{\circ}\right) . \quad \mathrm{E}_{\mathrm{t}}$

Toughness

Rangisetty Layer height $(0.2 \mathrm{~mm})$, extruder temperature $\left(240^{\circ} \mathrm{C}\right)$, bed temperature $\quad \sigma_{\mathrm{t}}$

et al. [10] $\left(90^{\circ} \mathrm{C}\right)$, print speed $(55 \mathrm{~mm} / \mathrm{s})$ and infill pattern (line, Concentric,

Triangular, and Honeycomb). $\quad E_{t}$

$\sigma_{\mathrm{f}}$

$E_{f}$

Bamiduro Orientation $\left(0^{\circ} / 90^{\circ},-45^{\circ} / 45^{\circ}\right) \quad \sigma_{\mathrm{t}}$

et al. [11]

Meng et Layer height $(0.1 \mathrm{~mm})$, orientation (vertical, , horizontal), printing speed $\sigma_{\mathrm{t}}$

al. [6] $(40 \mathrm{~mm} / \mathrm{s})$, extruder temperature $\left(235^{\circ} \mathrm{C}\right)$, bed temperature $\left(80^{\circ} \mathrm{C}\right)$,

composition (ABS,ABS/SiO $\left.2, \mathrm{ABS} / \mathrm{MMT}, \mathrm{ABS} / \mathrm{MWCNTs}, \mathrm{ABS} / \mathrm{CaCO}_{3}\right) \quad \sigma_{\mathrm{f}}$

$E_{f}$

Coogan et Bed temperature $\left(100^{\circ} \mathrm{C}, 125^{\circ} \mathrm{C}, 150^{\circ} \mathrm{C}\right)$, print speed $(1000,2000$,

al. [12]

$4000) \mathrm{mm} / \mathrm{min}$, layer height $(0.15,0.3,0.45 \mathrm{~mm})$, nozzle temperature

$\left(230{ }^{\circ} \mathrm{C}, 255^{\circ} \mathrm{C}, 280^{\circ} \mathrm{C}\right)$, fiber width $(0.4,0.6,0.8 \mathrm{~mm})$

Bond

strength

Longitudinal strength

Huang et Layer thickness $(0.1,0.2,0.3 \mathrm{~mm})$, raster angle $\left(45^{\circ} /-45^{\circ}, 30^{\circ} /-60^{\circ}, 0^{\circ} \quad \sigma_{\mathrm{t}}\right.$

al.[13]

$\left.190^{\circ}\right)$, printing speed $(20,40,60 \mathrm{~mm} / \mathrm{s})$, building orientation

(horizontal, lateral, vertical), bed temperature $\left(80^{\circ} \mathrm{C}\right)$, printing $\sigma_{\mathrm{f}}$

temperature $\left(235^{\circ} \mathrm{C}\right)$

Impact

strength

Koch et al. Print temperature $\left(250^{\circ} \mathrm{C}\right)$, bed temperature $\left(210^{\circ} \mathrm{C}\right)$, layer height $(0.2$
[14] $\mathrm{mm})$, raster angle $\left(0^{\circ},-45^{\circ} / 45^{\circ}, 90^{\circ}\right)$, travel speed $(2000 \mathrm{~mm} / \mathrm{min})$,

$\mathrm{mm})$, raster angle $\left(0^{\circ},-45^{\circ} / 45^{\circ}, 90^{\circ}\right)$, travel speed $(2000 \mathrm{~mm} / \mathrm{min})$,

$\sigma_{\mathrm{t}}$

solidity ratio $(0.6-1)$

Cantrell et Layer height $(0.1 \mathrm{~mm})$, printing temperature $\left(235^{\circ} \mathrm{C}\right.$

$\sigma_{\mathrm{t}}$

al. [15]

), bed temperature $\left(105^{\circ} \mathrm{C}\right)$, orientation (Horizontal, lateral, vertical ), raster angle $\left(-45^{\circ} / 45^{\circ}, 0^{\circ} / 90^{\circ}\right.$,

$\left.30^{\circ} /-60^{\circ}, 15^{\circ} /-75^{\circ}\right)$ 


\begin{tabular}{|lll|}
\hline Authors & Parameters and (levels) & Outputs \\
\hline Rayegani & Orientation $\left(0^{\circ}, 90^{\circ}\right)$, raster angle $\left(0^{\circ}, 45^{\circ}\right)$, raster width $(0.2032,0.558$ & $\sigma_{\mathrm{t}}$ \\
and. & $\mathrm{mm})$, air gap $(0.558,-0.00254 \mathrm{~mm})$ & \\
Onwubolu & & \\
\hline 16$]$ & & \\
\hline
\end{tabular}

Other studies adopted the potential of improving physical and mechanical properties of the raw material itself. Nanoparticles were prepared and mixed with the printing filament to produce a new one[6, 17-19]. Some research focuses on improving the overall mechanical properties of the 3D printed part by decreasing its anisotropy or increasing its isotropic behavior[20,21].They replaced the thermoplastic polymers that results in poor chemical and thermal properties by two-component epoxy resin[20],epoxy resin poses good chemical and physical properties and gives high-strength bonding, with light weight structures withstanding high static loads[22, 23]. Filippova et al. [21] impregnated ABS 3D printed samples in epoxy resin compound with different hardeners. $142 \%$ and $133 \%$ were achieved as an improvement in ultimate tensile strength depending on the hardener type. Instead of impregnation, Belter and Dollar [24] injected epoxy resin through ABS flexural specimens. This results in improving the overall part stiffness and strength by up to $25 \%$ and $45 \%$ respectively. Moreover, Jiang et al. [20] used epoxy as the main raw material in FDM technique to get the best use of its mechanical properties and print products can be used in harsh conditions. Tensile specimens were printed of a mixture of only epoxy and CNT giving a tensile strength of $55 \mathrm{MPa}$.

In this paper, ABS tensile specimens are printed with printing parameters based on the survey presented in Table1. A comparison between the results of many previous studies is held to decide on the best parameters to print with. Also using these printing parameters, another tensile specimens are printed to test a new filling technique. This technique is a post processing technique aims to improve the mechanical properties, reduce cost and weight. Hence the parts are printed with inner voids which reduces the part weight, time and cost of printing in turn. Then these voids are injected with low-cost, less dense resin which poses higher mechanical properties. To make the part sparse inside, voids could be designed and located precisely during design stage by CAD software, or slicing software manage these process through infill density parameter [25]. In this study, the parts are sparse by slicing software, three infill density are printed $(20 \%, 40 \%$ and $60 \%)$ and injected by epoxy resin that is less in price by $91 \%$. The infill pattern chosen is gyroid pattern to let the resin to spread entire the whole part. Tensile tests and morphology analysis are performed to investigate the improvement of this technique.

\section{Experimental}

\subsection{Materials and samples}

In this study, ABS (Acrylonitrile butadiene styrene) had been used as filament material, it was obtained from (AMTech 3D Printing company, Cairo, Egypt) with a diameter of $2.85 \mathrm{~mm}$, density of $1.1 \mathrm{~g} \mathrm{~cm}^{-3}$, and metal flow index of 41g/10min. Deco-pox 039 epoxy resin was obtained from (Pioneers for Polymers \& 
Chemicals PPC company, Alexandria, Egypt). The resin has a bisphenol-A base, and the hardener has polyamine one [26], Table 2 shows the resin properties.

Table 2

Physical and chemical properties for Deco-pox039

\begin{tabular}{|lll|}
\hline Property & Resin & Hardener \\
\hline Boiling point/Boiling range & $>200{ }^{\circ} \mathrm{C}$ & $>200{ }^{\circ} \mathrm{C}$ \\
\hline Flash point & $>150^{\circ} \mathrm{C}$ & $>100^{\circ} \mathrm{C}$ \\
\hline Density at $23^{\circ} \mathrm{C}$ & appr. $1.1 \mathrm{~g} \mathrm{~cm}^{-3}$ & appr. $1.03 \mathrm{~g} \mathrm{~cm}^{-3}$ \\
\hline Viscosity & appr. $1000 \mathrm{mPa} . \mathrm{s}$ & appr. $190 \mathrm{mPa} . \mathrm{S}$ \\
dynamic at $23^{\circ} \mathrm{C}$ & & \\
\hline Density of the mixture at $23^{\circ} \mathrm{C}$ & $1.1 \mathrm{~g} \mathrm{~cm}^{-3}$ & \\
\hline
\end{tabular}

Tensile specimens were designed according to ASTM638 type I [27], and printed on ultimaker ${ }^{3}$ with nozzle diameter $0.4 \mathrm{~mm}$ and Cura 4.8 slicing software in ideaspace company as shown in (Fig. 1).

\subsection{Methodology \\ 2.2.1 Printing $100 \%$ infill specimens}

In this study $100 \%$ infill ABS tensile specimens were printed with printing parameters that were precisely selected based on the literature in Table 1, the selected parameters are believed to give the best results as it were selected based on the previous experimental work done on this material regarding the results obtained in every study. Table 3 summaries the parameters used in the present study. After printing, tensile test was performed, all tensile tests in this research had been performed on German Zwick testing machine Z010. 
Table 3

Printing parameters for ABS

\begin{tabular}{|lll|}
\hline Printing temperature & $240^{\circ} \mathrm{C}$ \\
\hline Printing speed & $40 \mathrm{~mm} \mathrm{~s}^{-1}$ \\
\hline Layer thickness & $0.2 \mathrm{~mm}$ \\
\hline Build plate temperature & $100^{\circ} \mathrm{C}$ \\
\hline Printing orientation & Horizontal \\
\hline Raster angle & $0^{\circ}$ \\
\hline Infill pattern & Lines \\
\hline
\end{tabular}

\subsubsection{Filling technique}

In this technique, tensile specimens had been printed with inner voids to be injected with epoxy resin, ABS specimens were sparse inside using the slicing software. The software controls how dense the part is by infill percentage parameter, three percentages had been printed $20 \%, 40 \%$, and $60 \%$ with a pattern that allowed the resin to flow through the whole specimen, and two holes of $0.4 \mathrm{~mm}$ for injection and venting were drilled in the specimens (Fig. 2).

To identify the mechanical properties of the epoxy resin being used, tensile test had been done on decoPox039 Epoxy resin, two components A and B were mixed together under the predefined percentages, then the mix was poured into a custom-made silicone rubber mold in (Fig. 3a) and let for 7 days to fulfill the full curing as written in the product data sheet, the test was done following ASTM638 type I.

After testing the epoxy specimen and making sure about its properties, it was approved to be used as an injection material. Epoxy injection within the ABS printed tensile was done using a syringe, the syringe was immersed inside the specimen trough one of the holes and sealed very well, and the other hole was for venting. The syringe used was G16 to conform to the highly viscous epoxy. Injection process was in vertical orientation, syringe was immersed at the bottom and the direction of injection was against gravity to make sure the epoxy filled the whole specimen by reaching the top, (Fig. 4) shows the direction of injection. (Fig. 5) represents sections at different locations in a specimen to ensure epoxy flowed through the whole specimen. Tensile test was done - after seven days from specimens injection, the full curing time- on German Zwick testing machine Z010, with $10 \mathrm{KN}$ calibrated load cell, and crosshead speed of 5 $\mathrm{mm} \mathrm{min}^{-1}$. At least three samples for each case were tested. Morphology analysis on the fractured specimens had been done, as the fracture surfaces were observed via scanning electron microscope (SEM, JEOL JSM_5400LV). All the surfaces were gold-sputtered before observation and the observation was at an acceleration voltage of $15 \mathrm{KV}$.

\section{Results And Discussion}




\subsection{Results of Epoxy resin test}

The mechanical behavior of deco-Pox039 Epoxy resin is shown in (Fig. 6), the tensile test had been done on four specimens to take the average and give the best accurate result. The epoxy used in this paper have a resin of Aromatic bisphenol (bisphenol-A) and hardener of amino methylamine and phenyl methylamine. And the ultimate tensile strength obtained was $44.8 \mathrm{MPa}$ and elongation at break was of $12 \%$. This result is higher than the tensile strength obtained by Filippova et al[21],and it is related to the chemical composition hence the hardeners tested by Filippova et al. were triethylenetetramine (TETA) and polyethylene polyamine (PEPA) which resulted in tensile strength of 22.4 MPa and 22.7 MPa respectively. On the other hand, Halder et al[28],used a resin of bisphenol-A and amine-based hardener so their results was very close to the results in this paper as they recorded $41.92 \mathrm{MPa}$ as best tensile strength. $\mathrm{K}$. Agarwal and G. Agarwal [29],had tested the bisphenol-A resin with two different hardener types:

triethylenetetramine (TETA) and diaminodiphenyl methane (DDM) giving a strength of $52 \mathrm{MPa}$ and 83 $\mathrm{MPa}$ respectively. And when using bisphenol-F as a resin with aromatic amine hardener the strength reached $84 \mathrm{MPa}$ [30].

\subsection{Results of $100 \%$ infill ABS test}

(Fig. 7), represents the result of the tensile test on $100 \%$ infill printed ABS specimens with the parameters in Table 3, three specimens were tested, elongation at break was $7.4 \%$ and tensile strength was $36.3 \mathrm{MPa}$. This result is considered one of the best result obtained for $100 \%$ infill ABS tensile specimens. (Fig. 8), shows a comparison between the result of the present study, and most of the results obtained in the studies mentioned in Table 1, the variation in results ensures the influence of printing parameters on the mechanical properties of the printed part. Table 4 compares the printing parameters used in the present study to those used by T. Coogan et al.[12] as they got the nearest result to this study's result. Both of the two studies have very close parameters, the main difference is in layer height parameter as $0.2 \mathrm{~mm}$ layer height that is adopted in this research is believed to be the best height fulfilling the best boding between adjacent roads and consecutive layers

$[31,32]$.

Table 4. Comparison between printing parameters in the present study and in the nearest paper to this paper's result 


\begin{tabular}{|lll|}
\hline & $\begin{array}{l}\text { Present study (tensile strength: } 36.3 \\
\mathrm{MPa} \text { ) }\end{array}$ & $\begin{array}{l}\text { T. Coogan et al [12] (tensile strength: } \\
\mathbf{3 4 . 5} \mathrm{MPa} \text { ) }\end{array}$ \\
\hline $\begin{array}{l}\text { Printing } \\
\text { Temperature }\end{array}$ & $240^{\circ} \mathrm{C}$ & $280^{\circ} \mathrm{C}$ \\
\hline Bed Temperature & $100^{\circ} \mathrm{C}$ & $125^{\circ} \mathrm{C}$ \\
\hline Printing Speed & $40 \mathrm{~mm} \mathrm{~s}^{-1}$ & $2000 \mathrm{~mm} \mathrm{~min}^{-1} \cong 33.33 \mathrm{~mm} \mathrm{~s}^{-1}$ \\
\hline Layer Height & $0.2 \mathrm{~mm}$ & $0.3 \mathrm{~mm}$ \\
\hline Pattern & Lines & Lines \\
\hline Raster Angle & $0^{\circ}$ & $0^{\circ}$ \\
\hline
\end{tabular}

\subsection{Results of filling ABS test}

The effect of Epoxy resin injection within ABS printed part is represented in (Fig. 9), all printing parameters, injection material and method were controlled, the variables were infill density of ABS while printing and the injected volume of epoxy in turn.

Apparently, the results are very close, average tensile strength for 20\% ABS infill-80\% epoxy injection (20B$80 \mathrm{E}$ ) is $24.77 \mathrm{MPa}$, for $40 \%$ ABS infill-60\% epoxy injection (40B-60E) is $27.03 \mathrm{MPa}$ and $21.8 \mathrm{MPa}$ for $60 \%$ ABS infill-40\% epoxy injection (60B-40E). Although the strength of $40 \%$ infill is marked the best but by analyzing the weight and corresponding printing time, (20B-80E) gives the optimum strength to printed weight ratio Table 5. Furthermore, the preference of $20 \%$ infill ABS injected with epoxy to the pure $100 \%$ infill printed ABS was investigated, and it was concluded that by reducing $56 \%$ of the part weight -in $20 \%$ infill-, the product mechanical strength reaches $68 \%$ of the printed part with $100 \%$ infill, and the strength to printed weight ratio is increased by $151 \%$, Table 5 . Strength to printed weight ratio is analyzed in this study rather than the common strength to weight ratio; because the injected epoxy resin has the same density of ABS filament used $-1.1 \mathrm{~g} \mathrm{~cm}^{-3}$-. Some others thermoplastic filament material like PLA which poses higher density (1.17-1.24 $\mathrm{g} \mathrm{cm}^{-3}$ ) [8] might show better results when injected with similar epoxy types. Results of the previous tests indicate adequate adhesion between epoxy and ABS. Since the effective surface is considered the main parameter to give best adhesion, and one of the techniques to enhance the effective surface is roughening it but to an acceptable level. -As if the surface is more rough the adhesion stress would decrease-[33]. And hence one of the themes of FDM process is the moderate surface finish, so that would fulfill good adhesion between epoxy and ABS. (Fig. 10), represents sections in $20 \%, 40 \%$ and $60 \%$ infill specimens after injection and testing. 
Table 5

Physical and mechanical properties obtained from ABS test

\begin{tabular}{|llllllll|}
\hline & $\begin{array}{l}\text { Ultimate } \\
\text { tensile } \\
\text { strength } \\
\text { (MPa) }\end{array}$ & $\begin{array}{l}\text { Strain at } \\
\text { ultimate } \\
\text { strength } \\
\text { (\%) }\end{array}$ & $\begin{array}{l}\text { Printing } \\
\text { time }\end{array}$ & $\begin{array}{l}\text { Printed } \\
\text { weight } \\
\text { (g) }\end{array}$ & $\begin{array}{l}\text { Printed } \\
\text { weight } \\
\text { reduction } \\
\text { (100\%) }\end{array}$ & $\begin{array}{l}\text { Strength/printed } \\
\text { weight ratio }\end{array}$ & $\begin{array}{l}\text { Specimen } \\
\text { weight } \\
\text { (g) }\end{array}$ \\
\hline $\begin{array}{l}100 \% \\
\text { ABS } \\
\text { infill }\end{array}$ & 36.30 & 7.40 & $1 \mathrm{~h} 36 \mathrm{~m}$ & 16 & $0 \%$ & 2.32 & 16 \\
\hline $\begin{array}{l}20 \% \\
\text { ABS } \\
\text { infill }\end{array}$ & 24.77 & 6.27 & $59 \mathrm{~m}$ & 7 & $56.25 \%$ & 3.50 & 16 \\
\hline $\begin{array}{l}40 \% \\
\text { ABS } \\
\text { infill }\end{array}$ & 27.03 & 6 & $1 \mathrm{~h} 8 \mathrm{~m}$ & 9 & $43.75 \%$ & 3 & \\
\hline $\begin{array}{l}60 \% \\
\text { ABS } \\
\text { infill }\end{array}$ & 21.80 & 7.20 & $1 \mathrm{~h} 29 \mathrm{~m}$ & 12 & $25 \%$ & 1.80 & \\
\hline
\end{tabular}

\section{Morphology Analysis}

Results for morphology analysis are shown in (Fig. 11), it illustrates the bonding between the adjacent roads of ABS filament in the same layer, and shows the bonding between the consecutive ABS layers. The first remark is that roads cross-sections are not circular anymore and that due to the compression induced from the layers on each others. The bonding between adjacent roads is on more than $50 \%$ of its height, when notice the lines in (Fig. 11a), it could be concluded that the bonding height is between 90 and 170 microns. The gaps between consecutive layers are represented by lines in (Fig. 11b) and the gap height is between 18 to 21 microns. The trans-granular cleavage shown in each road cross-section indicates the brittle fracture mode of the material, (Fig. 11c).

(Fig. 12), shows SEM micrographs of an overview for three sections in (20B-80E), (40B-60E) and (60B$40 \mathrm{E})$ specimens $(a, b$ and $c)$ respectively. In the micrographs of the injected ABS specimens the contact surfaces between epoxy and ABS could be marked indicating super adhesion. Small discrete surface areas inside ABS specimens that were designed by printing software, helped to make it fully composite as the epoxy was immersed through the whole part. (Fig. 13), representing the three coated sections before being examined in the microscope.

By going deep in (20B-80E) specimen (Fig. 14), there are three levels of the ABS road as the mechanical fracture leaves unpaved surface in (Fig. 14b), in (Fig. 14c) there is perfect bond between epoxy and ABS with a vital defect in epoxy resin mix indicated some air bubbles, (Fig. 14d) and (Fig. 14e) indicates different levels of fracture in both epoxy and ABS with beach marks to ensure the brittle fracture and more air bubbles appear. 
The same phenomena were recognized in (Fig. 15) and (Fig. 16) representing (40B-60E) and (60B-40E) specimens respectively. In (Fig. 15b) is a magnified image of (Fig. 15a) where the brittle fracture is obvious and also it refers to discontinuity in injection. (Fig. 15d) is a magnified image of (Fig. 15c) and it shows 50 and 35 micron air bubbles in Epoxy mix. In (Fig. 16a) representing the fracture, it was just before a relative large air bubble and also there is another one that was collapsed by the fracture, (Fig. 16b) represents epoxy that is covering some sheared filaments.

\section{Conclusion}

- Printing parameters highly affect the mechanical properties of the printed part, printing parameters used in the present study is highly recommended as it gave one of the best results obtained for ultimate tensile strength of $-36.3 \mathrm{MPa}$ -

- The presented injection filling technique, could be considered a promising technique; as it reduces the printing time and cost aiming to sparse the part, these spares are filled simply and easily with a low-cost material and the overall result is improving the strength to printed weight ratio. This improvement was by $151 \%$ in case of (20B-80E) specimens and $129 \%$ in case of (40B-60E) specimens, but in case of $(60 \mathrm{~B}-40 \mathrm{E})$ there was not any improvement and that mainly because of the relative low volume of injected epoxy within these specimens.

- Injection filling technique is a post process technique and it could follow any 3D printing process not only FDM.

- Epoxy resin as a filling material was a good choice due to its higher toughness and tensile strength. 1 gram of Deco-pox039 resin injected within ABS specimens is lower in price than $1 \mathrm{gram}$ of printed ABS by $91 \%$. However, epoxy resin has many types so the best selection would became after studying the physical, chemical and mechanical properties needed.

- The denser and more discrete the voids are, the best adhesion between epoxy and the printed part.

- Epoxy resin mixture should be vacuumed before injection and also the printed part should be degassed while injection to avoid air bubbles induction.

- The presented filling technique could show more potential, the less the injected material is in density and the higher it is in mechanical properties in comparison with the thermoplastic printed material.

- The presented filling technique could show high potential in various application which requires light structures. Hence the trend in racing cars in Formula is to lighten the car weight, and replacing the metal parts by lightweight printed plastic ones, this technique could applied to reinforce these parts [1]. Also the strength-to-weight ratio is considered a vital concept in aerospace industry, as adding $100 \mathrm{Kg}$ of weight can increase the expense of an airline to come over $\$ 2.5$ million in fuel over an aircraft's lifetime. The filling technique could improve the properties of AM components that have been immersed in this industry significantly[1]. And finally, in cultural preserving field historical monuments are being scanned to print identical ones putting them in exhibitions or shops[5]. The presented technique could not only reduce the cost but also it could take the mechanical properties of the printed parts to a high level. 


\section{Abbreviations}

$\sigma_{t}$ Tensile strength

$\sigma_{\mathrm{f}}$ Flexural strength

$E_{t}$ Elastic modulus

$E_{f}$ Flexural modulus

\section{Declarations}

Funding

The authors declare that no funds, grants, or other support were received during the preparation of this manuscript.

Competing Interests

The authors have no relevant financial or non-financial interests to disclose.

Author Contributions

All authors contributed to the study conception and design. Material preparation, data collection were performed by [Heba Hussam]. Data analysis was performed by [Heba Hussam] and [Yasser Abdelrhman]. The first draft of the manuscript was written by [Heba Hussam]. All authors commented on previous versions of the manuscript. All authors read and approved the final manuscript.

\section{References}

1. Niaki MK, Nonino F (2018) Industries and Applications. In:Pham DT(ed) The management of additive manufacturing. Springer, pp 37-66. https://doi.org/10.1007/978-3-319-56309-1

2. Ćwikła G, Grabowik C, Kalinowski K et al (2017) The influence of printing parameters on selected mechanical properties of FDM / FFF 3D-printed parts. ModTech Int Conf. Inds Eng. V14-17. https://doi.org/10.1088/1757-899X/227/1/012033

3. Hanssen J, Moe ZH, Tan D et al (2015) Rapid prototyping in manufacturing. In: Nee AYC (ed) Handbook of Manufacturing Engineering and technology. Springer, pp.2505-2523. https://doi.org /10.1007/978-1-4471-4670-4

4. Abu M, Khondoker H, Asad A, Sameoto D (2018) Printing with mechanically interlocked extrudates using a custom bi-extruder for fused deposition modelling. Rapid Prototyp J 8(4): 248-257 https://doi.org/10.1108/RPJ-03-2017-0046 
5. Ngo TD, Kashani A, Imbalzano G, et al (2018) Additive manufacturing (3D printing): A review of materials, methods, applications and challenges. Compos Part B Eng 143:172-196. https://doi.org/10.1016/j.compositesb.2018.02.012

6. Meng S, He H, Jia Y, et al (2017) Effect of nanoparticles on the mechanical properties of acrylonitrile-butadiene-styrene specimens fabricated by fused deposition modeling. J Appl Polym Sci 134:1-9. https://doi.org/10.1002/app.44470

7. Shojib Hossain M, Espalin D, Ramos J, et al (2014) Improved Mechanical Properties of Fused Deposition Modeling-Manufactured Parts Through Build Parameter Modifications. J Manuf Sci Eng 136:061002. https://doi.org/10.1115/1.4028538

8. Yao T, Ye J, Deng Z, et al (2020) Tensile failure strength and separation angle of FDM 3D printing PLA material: Experimental and theoretical analyses. Compos Part B 188:107894. https://doi.org/10.1016/j.compositesb.2020.107894

9. Samykano M, Selvamani SK, Kadirgama K, et al (2019) Mechanical property of FDM printed ABS: influence of printing parameters. Int J Adv Manuf Technol 102:2779-2796. https://doi.org/10.1007/s00170-019-03313-0

10. Rangisetty S, Peel LD (2017) The effect of infill patterns and annealing on mechanical. the ASME Conference SMASIS2017-4011. 1-12 http://proceedings.asmedigitalcollection.asme.org

11. Bamiduro O, Owolabi G, Haile M A, Riddick J C (2019) The in fl uence of load direction, microstructure, raster orientation on the quasi-static response of fused deposition modeling ABS. Rapid Prototyp J.25(3): 462-472 https://doi.org/10.1108/RPJ-04-2018-0087

12. Coogan TJ, Kazmer DO (2017) Bond and part strength in fused deposition modeling. Rapid Prototyp J 23:414-422. https://doi.org/10.1108/RPJ-03-2016-0050

13. Huang B, Meng S, He H, et al (2018) Study of Processing Parameters in Fused Deposition Modeling Based on Mechanical Properties of Acrylonitrile-Butadiene-Styrene Filament. Polym. Eng. Sci.1-9. https://doi.org/10.1002/pen.24875

14. Koch C, Hulle L Van, Rudolph N (2017) Investigation of mechanical anisotropy of the fused filament fabrication process via customized tool path generation. Addit Manuf 16:138-145. https://doi.org/10.1016/j.addma.2017.06.003

15. Cantrell J, Rohde S,DiSandro L et al (2016) Experimental Characterization of the Mechanical Properties of 3D Printed ABS and Polycarbonate Parts. In:Yoshida S, Lamberti L, Sciammarella C (eds) Advancement of Optical Methods in Experimental Mechanics.Springer, 3: 89-105 https://doi.org/10.1007/978-3-319-41600-7

16. Rayegani F, Onwubolu GC (2014) Fused deposition modelling (fdm) process parameter prediction and optimization using group method for data handling (gmdh) and differential evolution (de). Int $J$ Adv Manuf Technol 73:509-519. https://doi.org/10.1007/s00170-014-5835-2

17. Zhu D, Ren Y, Liao G, et al (2017) Thermal and mechanical properties of polyamide 12 / graphene nanoplatelets nanocomposites and parts fabricated by fused deposition modeling. J Appl polymer Sci 45332:1-13. https://doi.org/10.1002/app.45332 
18. Nabipour M, Akhoundi B (2020) An experimental study of FDM parameters effects on tensile strength , density, and production time of ABS / Cu composites. Elastomers and Plastics. 1-19. https://doi.org/10.1177/0095244320916838

19. Jo W, Kwon O, Moon M (2018) Investigation of in fl uence of heat treatment on mechanical strength of FDM printed 3D objects. Rapid Prototyp J 24(3): 615-622 https://doi.org/10.1108/RPJ-06-20170131

20. Jiang Q, Zhang H, Rusakov D, Bismarck A (2021) Additive Manufactured Carbon Nanotube/Epoxy Nanocomposites for Heavy-Duty Applications. Applied Polymers Materials 93-97. https://doi.org/10.1021/acsapm.0c01011

21. Slavkina VE, Shitov AO, Stuchebrov SG, Miloichikova IA (2020) Study of the tensile strength of a polymer composite material based on ABS-plastic and impregnated in epoxy resin with different types of hardener. J. Phys.: Conf. Ser. 1990012015 https://doi.org/10.1088/17426596/1990/1/012015

22. Gao C, Yu T, Sun J, et al (2021) A phosphate covalent organic framework: Synthesis and applications in epoxy resin with outstanding fire performance and mechanical properties. Polym Degrad Stab 190:109613. https://doi.org/10.1016/j.polymdegradstab.2021.109613

23. Kasper Y, Albiez M, Ummenhofer T, et al (2021) Application of toughened epoxy-adhesives for strengthening of fatigue-damaged steel structures. Constr Build Mater 275:121579. https://doi.org/10.1016/j.conbuildmat.2020.121579

24. Chang W, Rose LRF, Islam MS, et al (2021) Strengthening and toughening epoxy polymer at cryogenic temperature using cupric oxide nanorods. Compos Sci Technol 208:108762. https://doi.org/10.1016/j.compscitech.2021.108762

25. Belter JT, Dollar AM (2015) Strengthening of 3D Printed Fused Deposition Manufactured Parts Using the Fill Compositing Technique. PLoS ONE 10(4): e0122915. doi:10.1371/journal.pone.0122915

26. Deco-Pox 039 (MSDS) 1

27. E3-95 (2016) Standard Practice for Preparation of Metallographic Specimens. ASTM Int 82:1-15. https://doi.org/10.1520/D0638-14.1

28. Halder S, Ghosh PK, Goyat MS, Ray S (2013) Ultrasonic dual mode mixing and its effect on tensile properties of SiO 2 -epoxy nanocomposite. J. Adhes. Sci. Technol. 4243:111-124. https://doi.org/10.1080/01694243.2012.701510

29. Agarwal KK, Agarwal G (2019) A study of mechanical properties of epoxy resin in presence of a study of mechanical properties of epoxy

30. Bajpai A, Wetzel B (2019) Tensile testing of epoxy-based thermoset system prepared by different methods. 1-8. https://doi.org/10.20944/preprints201907.0143.v1

31. Luzanin O, Movrin D, Guduric V (2019) Impact of processing parameters on tensile strength , inprocess crystallinity and mesostructure in FDM-fabricated PLA specimens. Rapid Prototyp J 8:13981410. https://doi.org/10.1108/RPJ-12-2018-0316 
32. Vishwas M, Basavaraj CK (2017) Studies on Optimizing Process Parameters of Fused Deposition Modelling Technology for ABS. Mater Today Proc 4:10994-11003.

https://doi.org/10.1016/j.matpr.2017.08.057

33. Bürenhaus F, Moritzer E, Hirsch A (2019) Adhesive bonding of FDM-manufactured parts made of ULTEM 9085 considering surface treatment, surface structure, and joint design. Welding in the World 63:1819-1832 https://doi.org/10.1007/s40194-019-00810-4

\section{Figures}

(a)
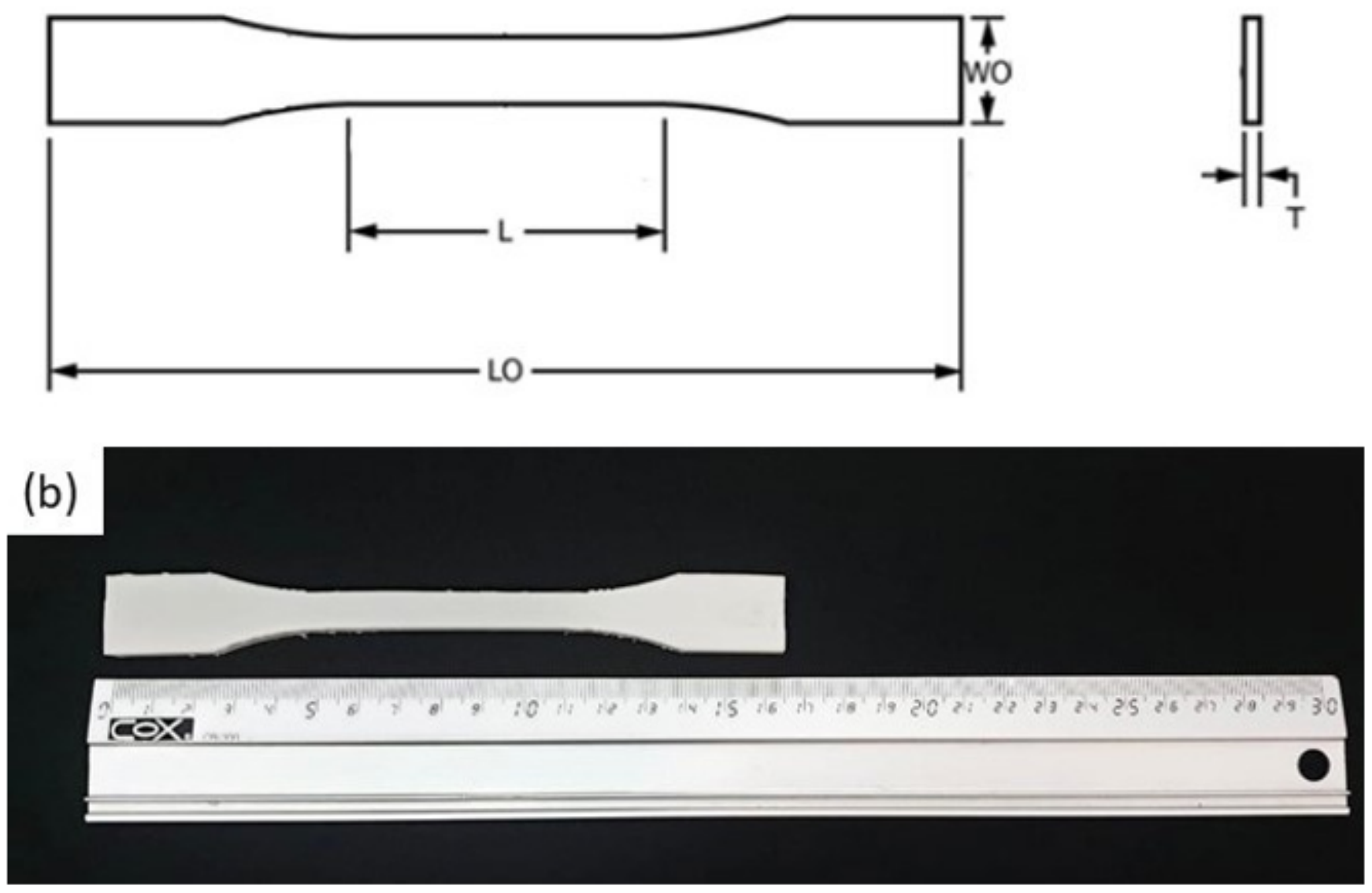

Figure 1

Specimen geometry according to ASTM D638 standard (a), printed tensile specimen (b) 
(a)
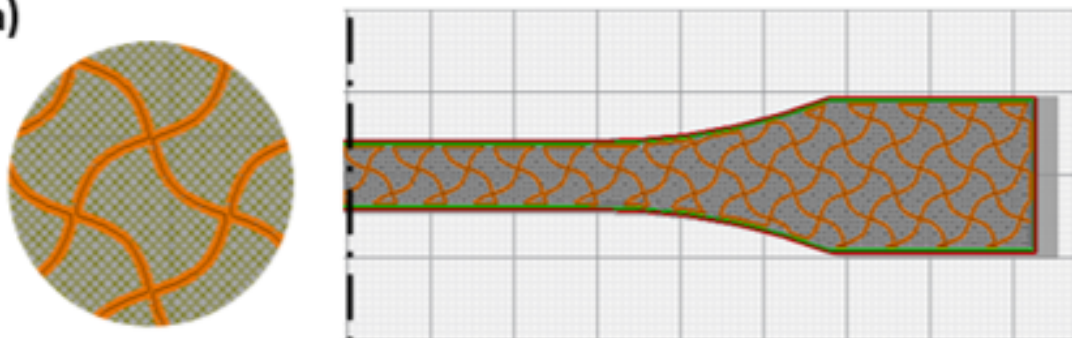

(b)


(c)
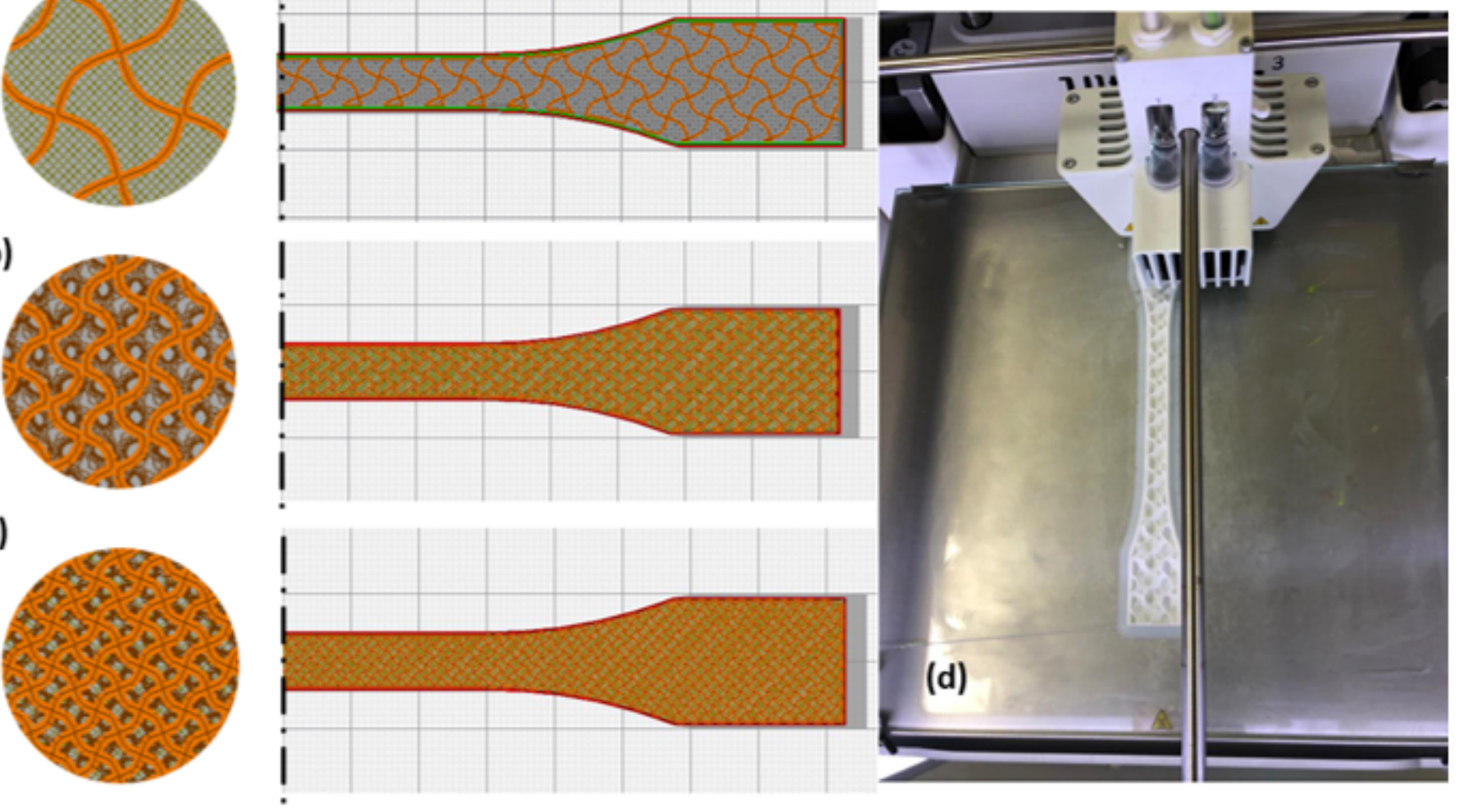

(d)

\section{Figure 2}

$20 \%$ infill ABS tensile specimen (a), 40\% infill ABS tensile specimen (b), $60 \%$ infill ABS tensile specimen (c), and $20 \%$ infill ABS specimen while printing on Ultimaker ${ }^{3}$ (d) 



Figure 3

Silicon mold for casting epoxy (a), casted epoxy tensile specimen (b), and epoxy specimen during testing (c) 


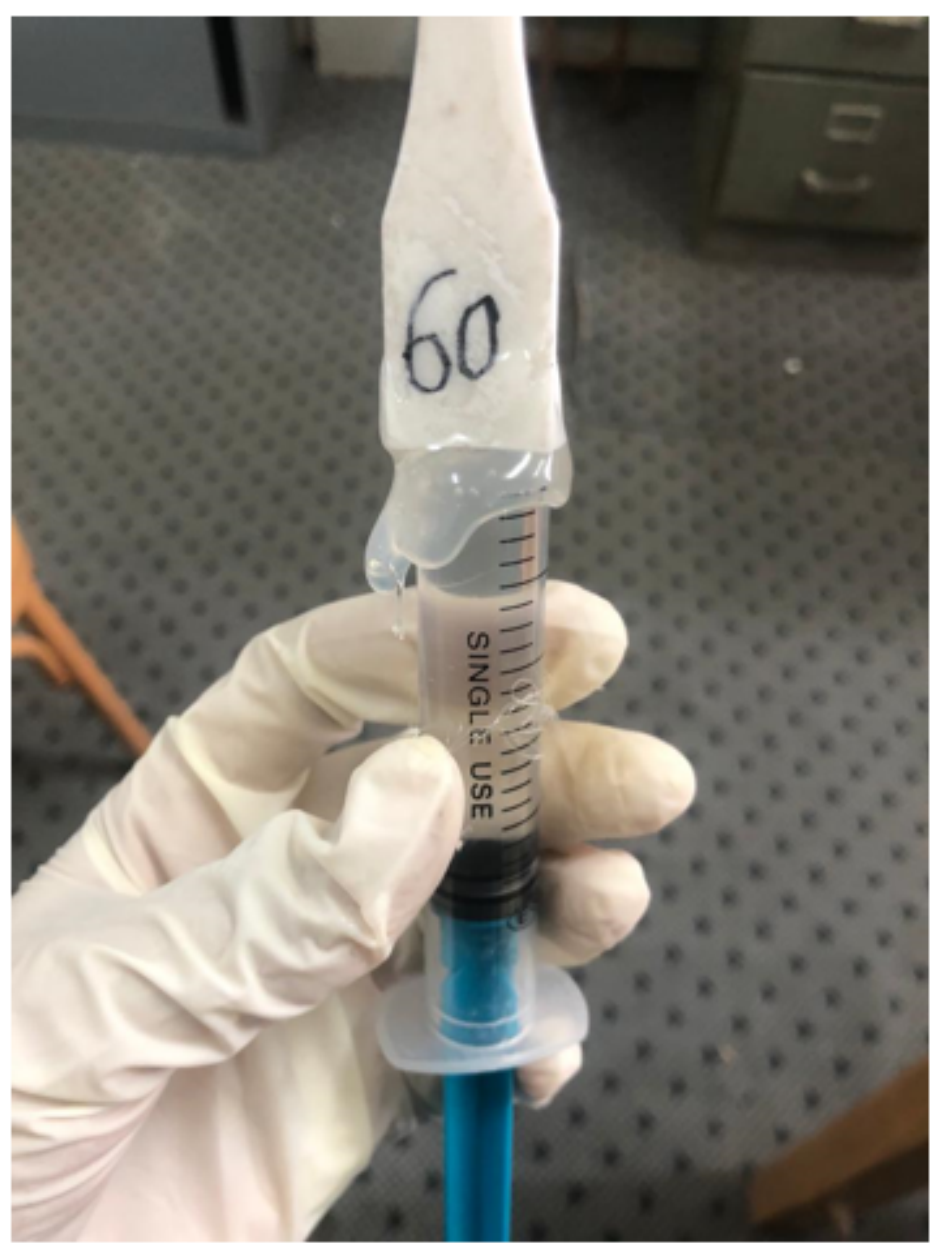

Figure 4

Injection process of $60 \%$ infill tensile specimen 


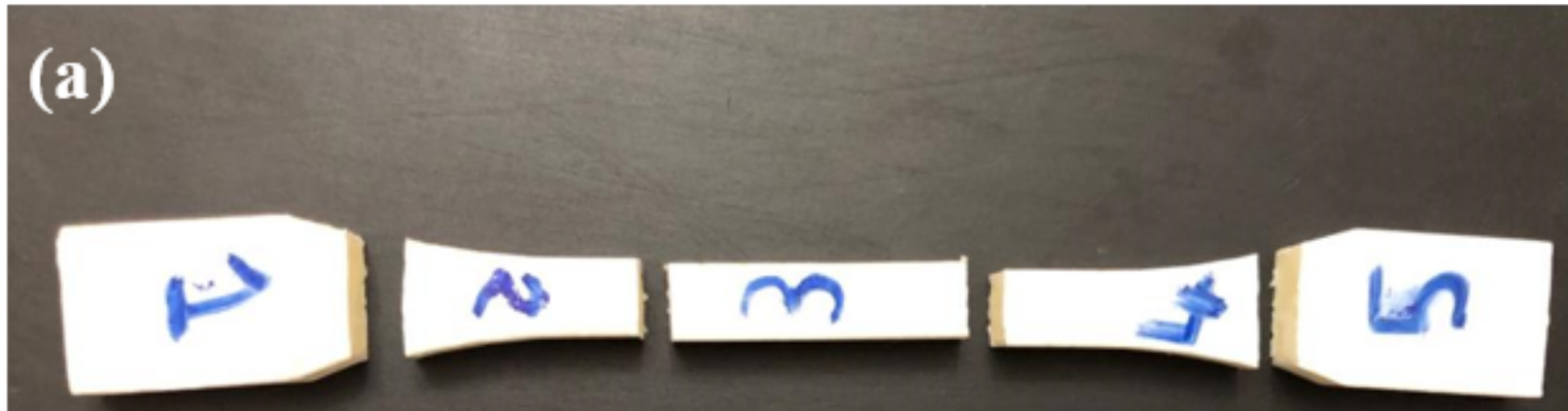

(b)

\section{Figure 5}

Sections in injected tensile specimen (a), top view of the sections (b) 


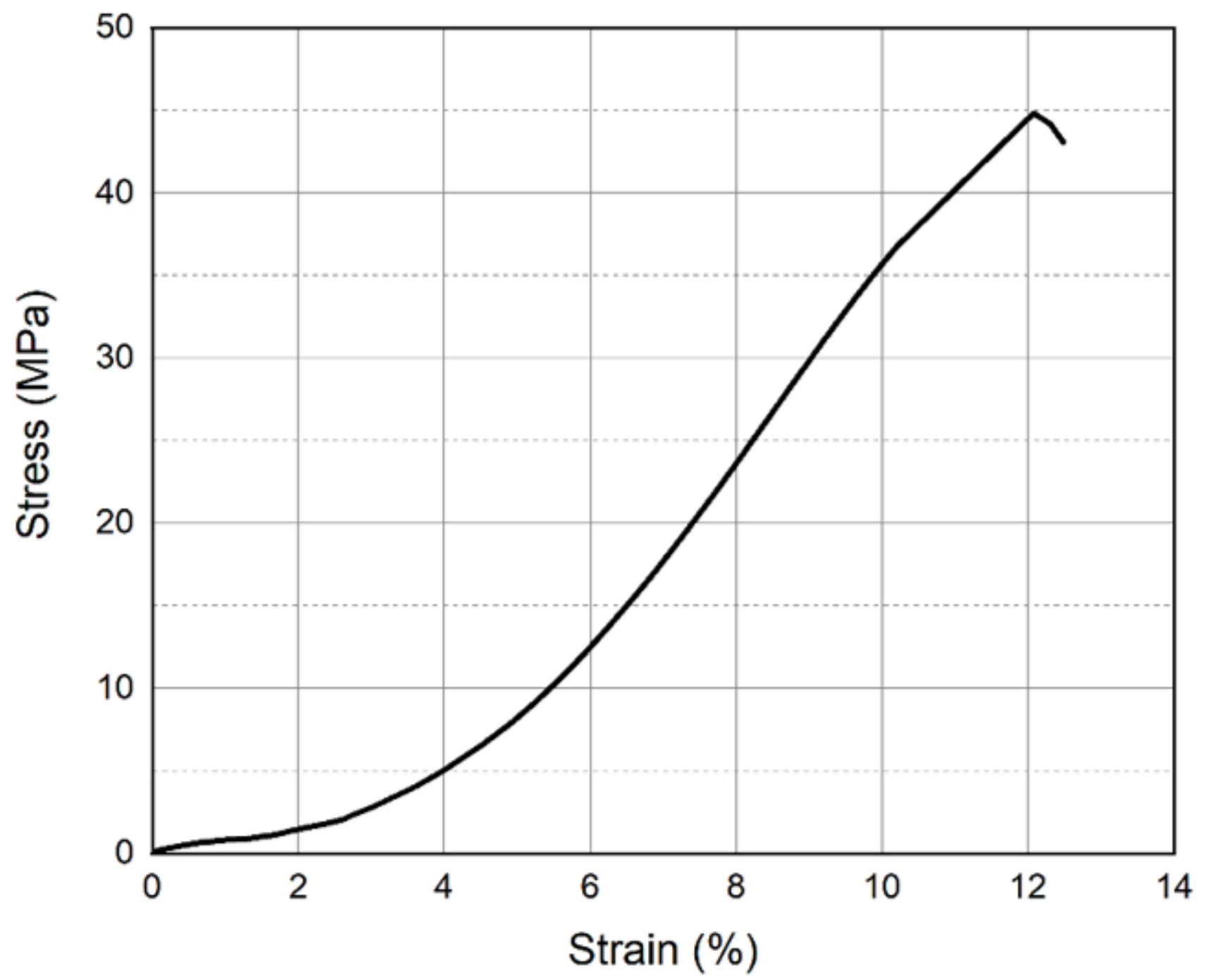

Figure 6

Deco-pox039 average tensile test result 




Figure 7

Results of $A B S 100 \%$ infill tensile test 




Figure 8

Tensile strength values reported by other researchers for $100 \%$ infill ABS compared with the obtained one by present study 


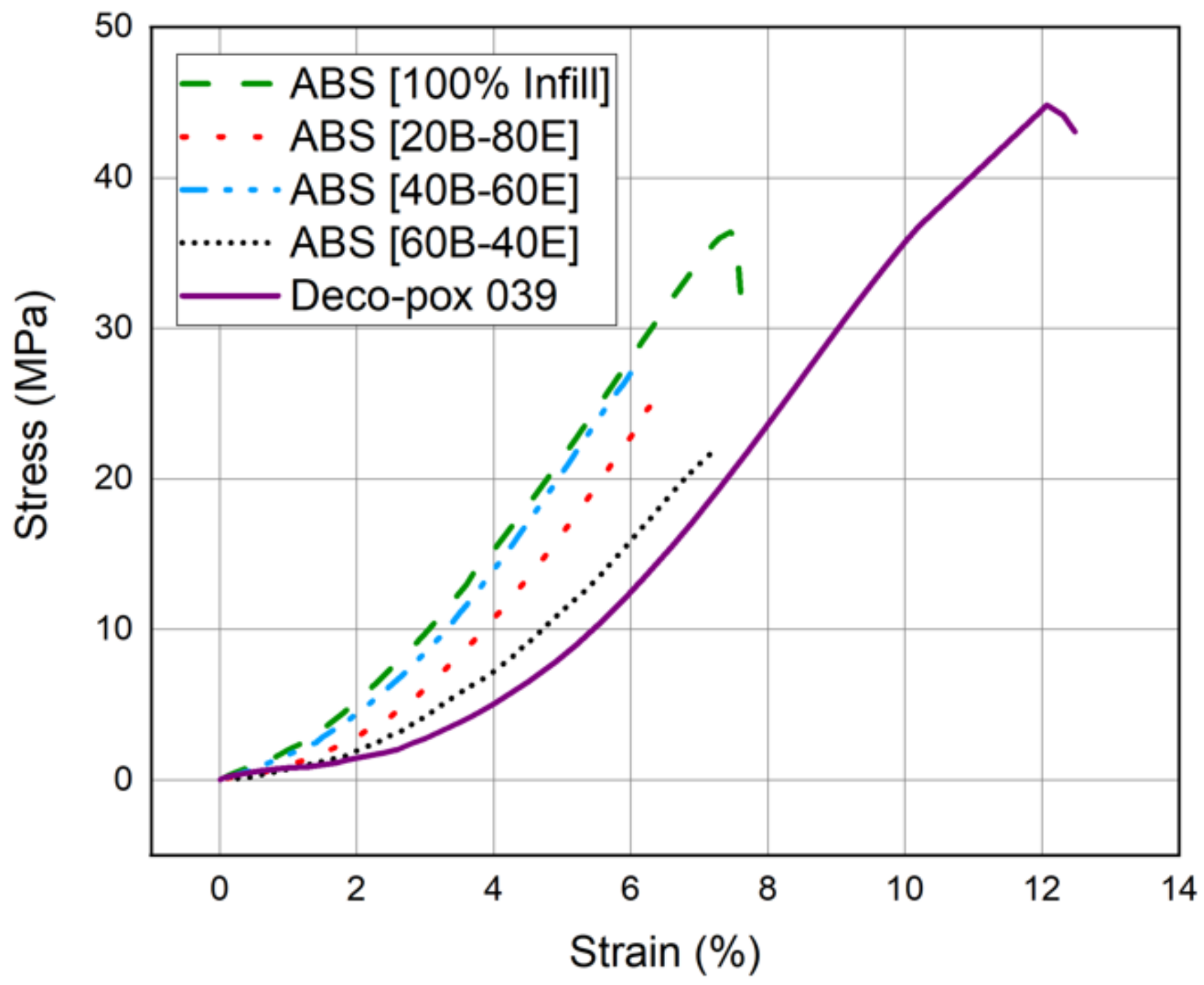

Figure 9

Results of composition technique in $20 \%, 40 \%$ and $60 \%$ infill in comparison with $100 \%$ ABS infill 


\section{(a)
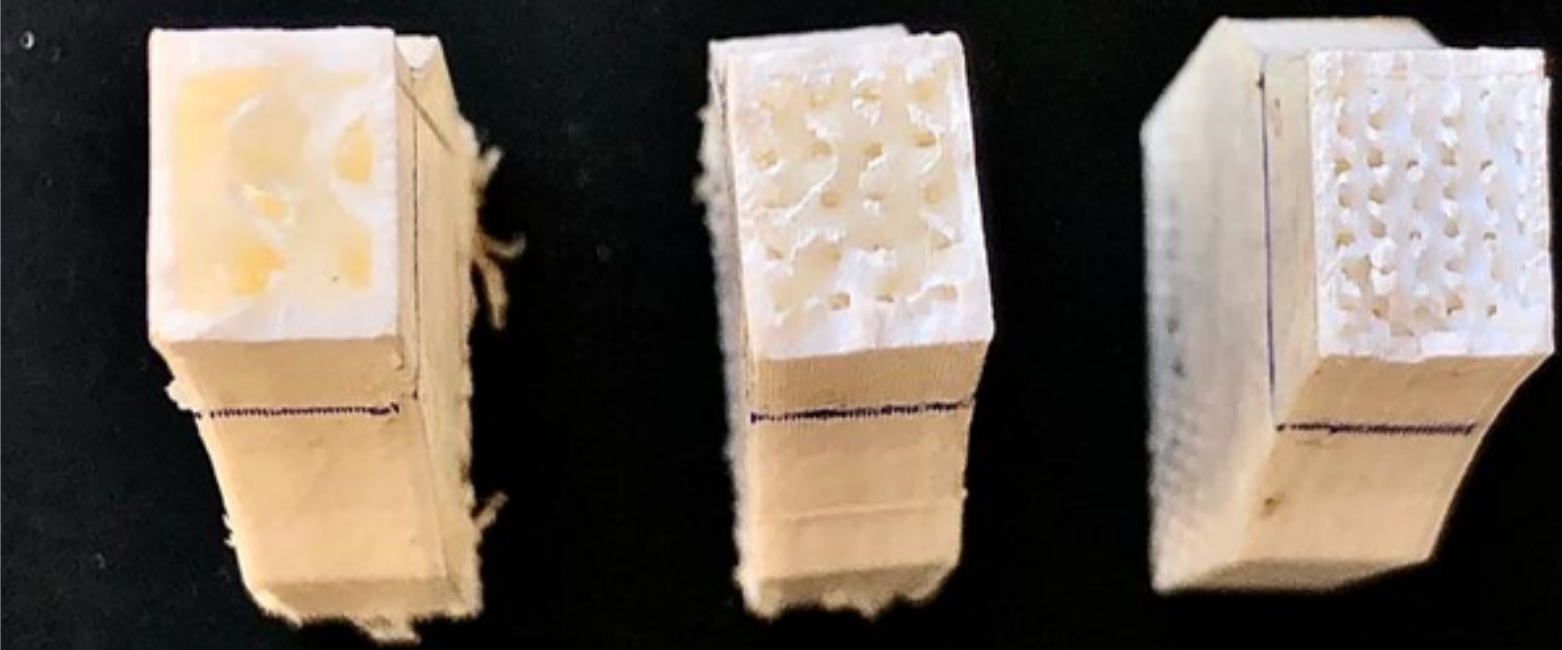

\section{Figure 10}

Sections in tested injected ABS specimens with infill: $20 \%$ (a), 40\% (b) and $60 \%$ (c) 
(a)

(b)

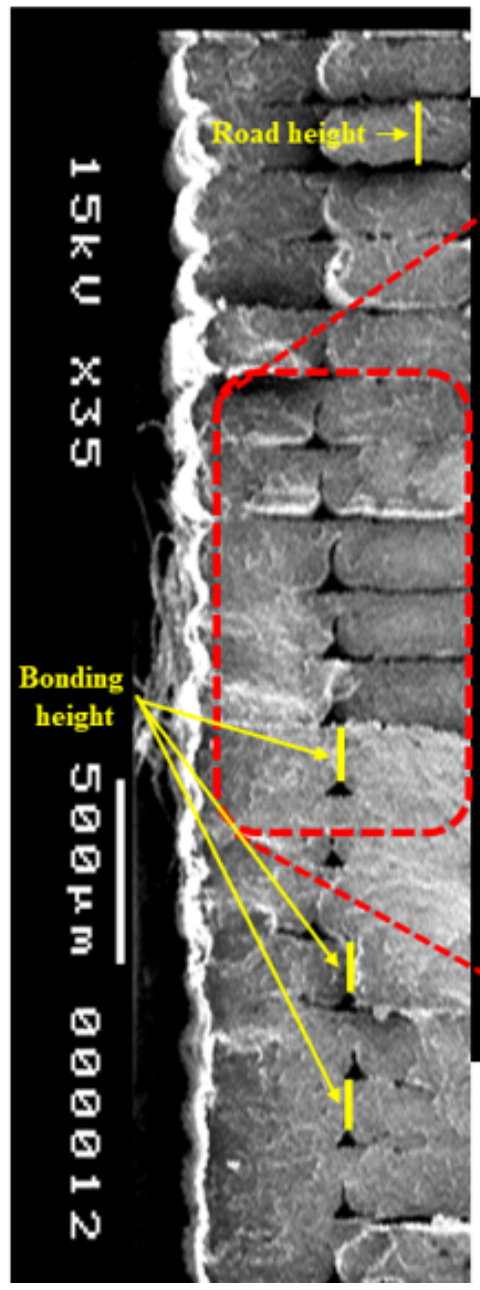

(c)

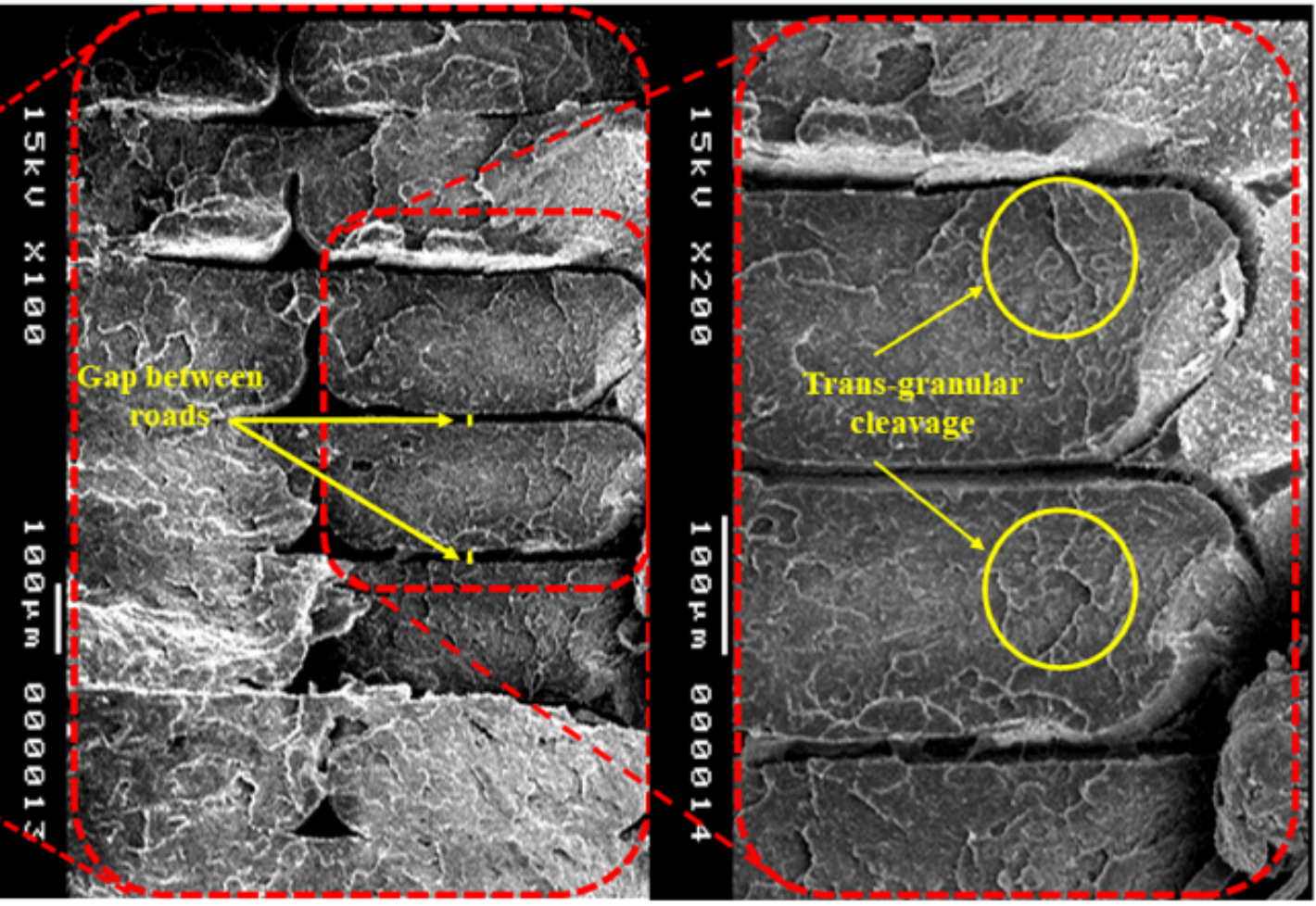

\section{Figure 11}

SEM micrograph in ABS specimens: overview for two adjacent roads in different consecutive layers (a), bonding in six consecutive layers (b), and the circles indicates the trans-granular cleavage in each road (c)




Figure 12

SEM micrographs for: (20B-80E) (a), (40B-60E) (b) and (60B-40E) specimens (c)

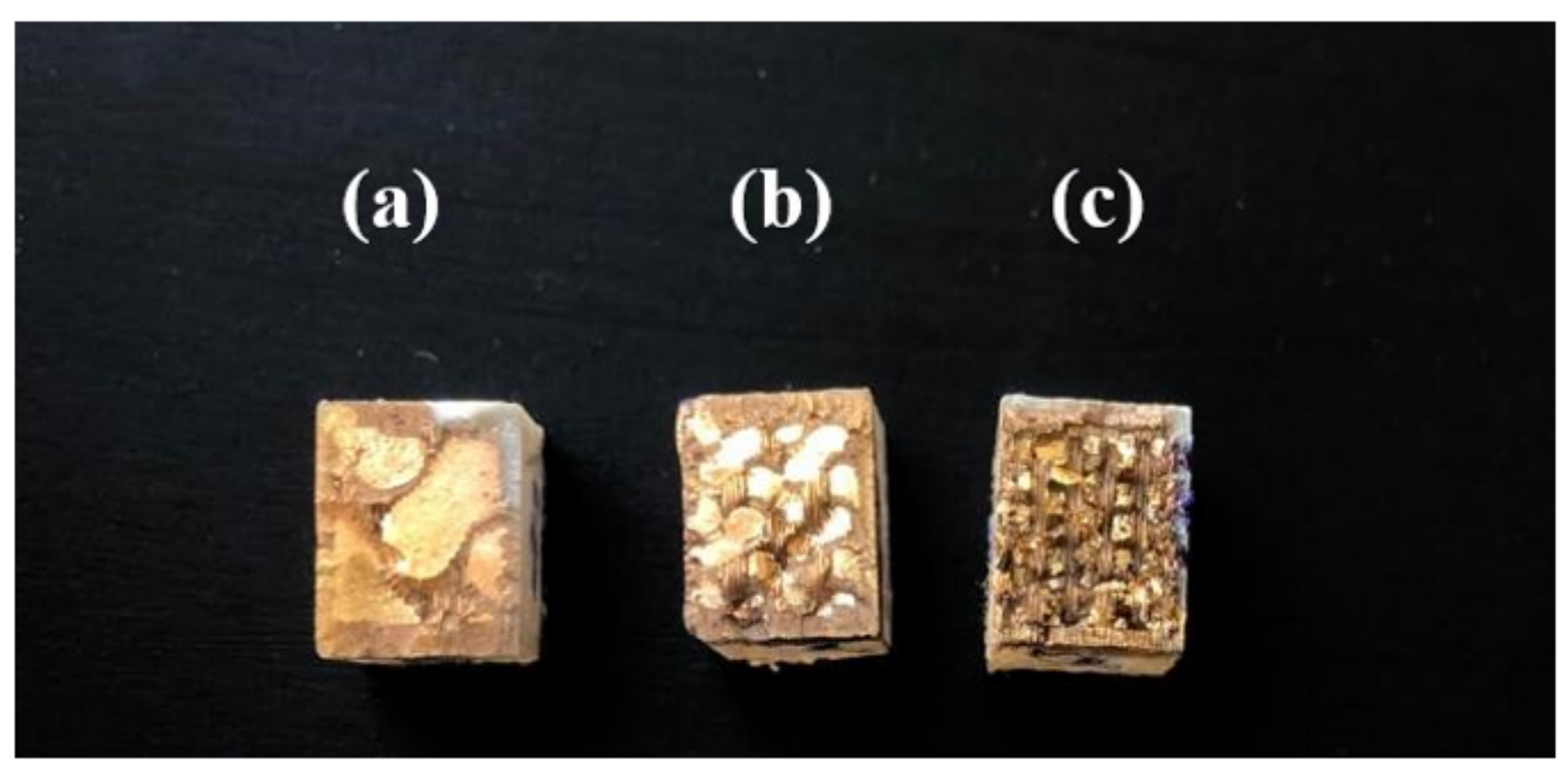

Figure 13

Coated sections in: (20B-80E) (a), (40B-60E) (b) and (60B-40E) specimens (c) 

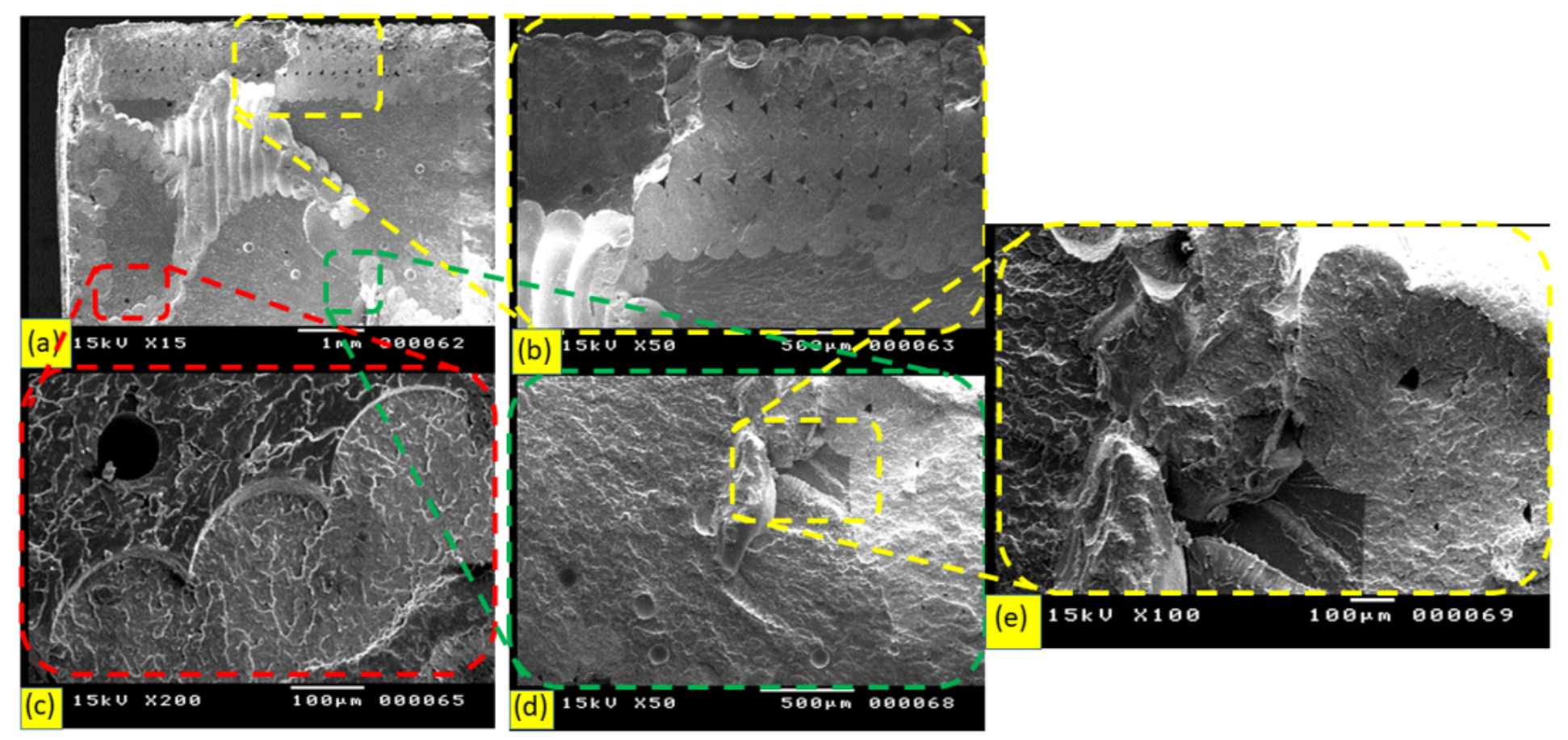

Figure 14

SEM micrographs in (20B-80E) 


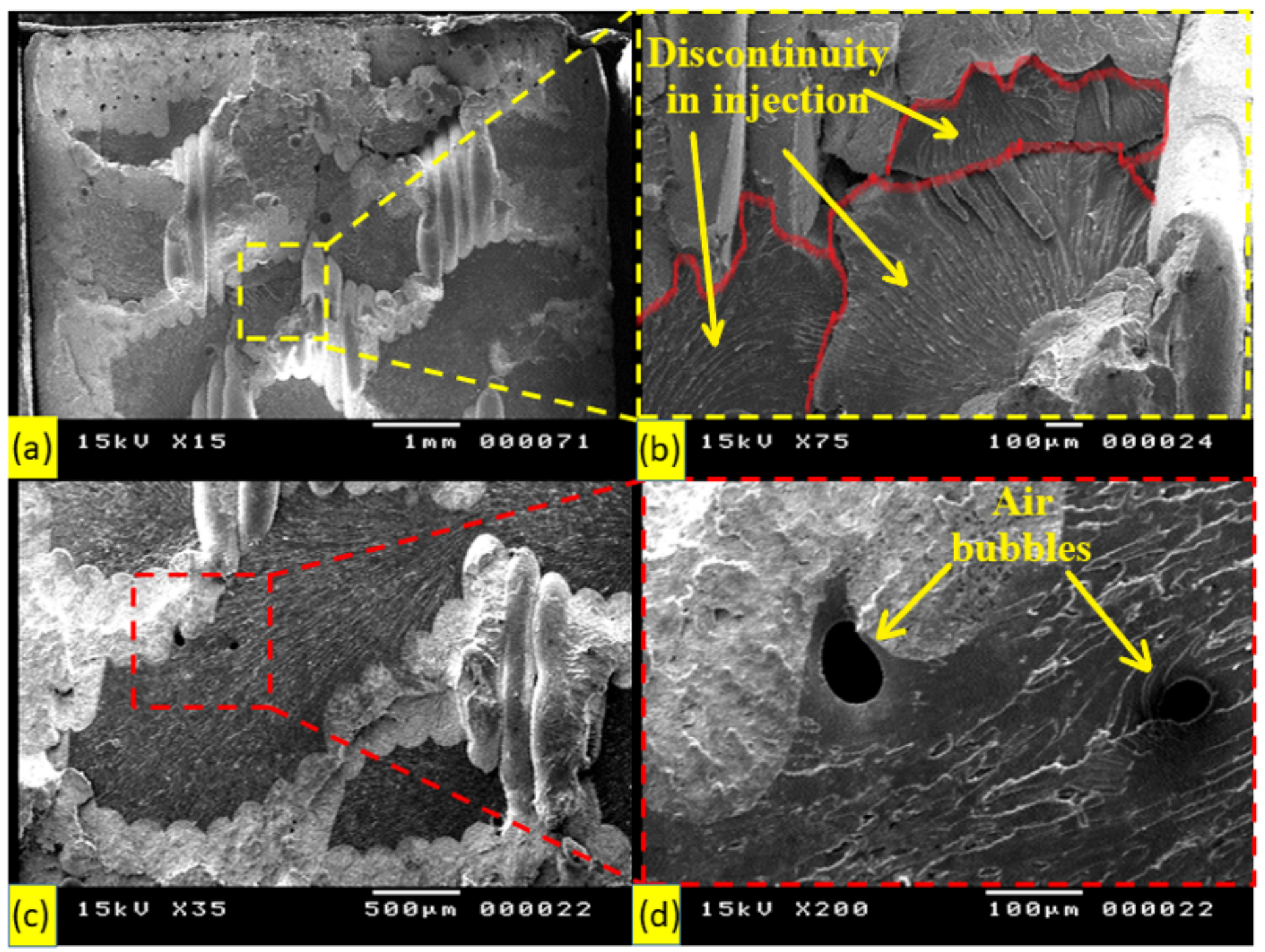

Figure 15

SEM micrographs in (40B-60E)

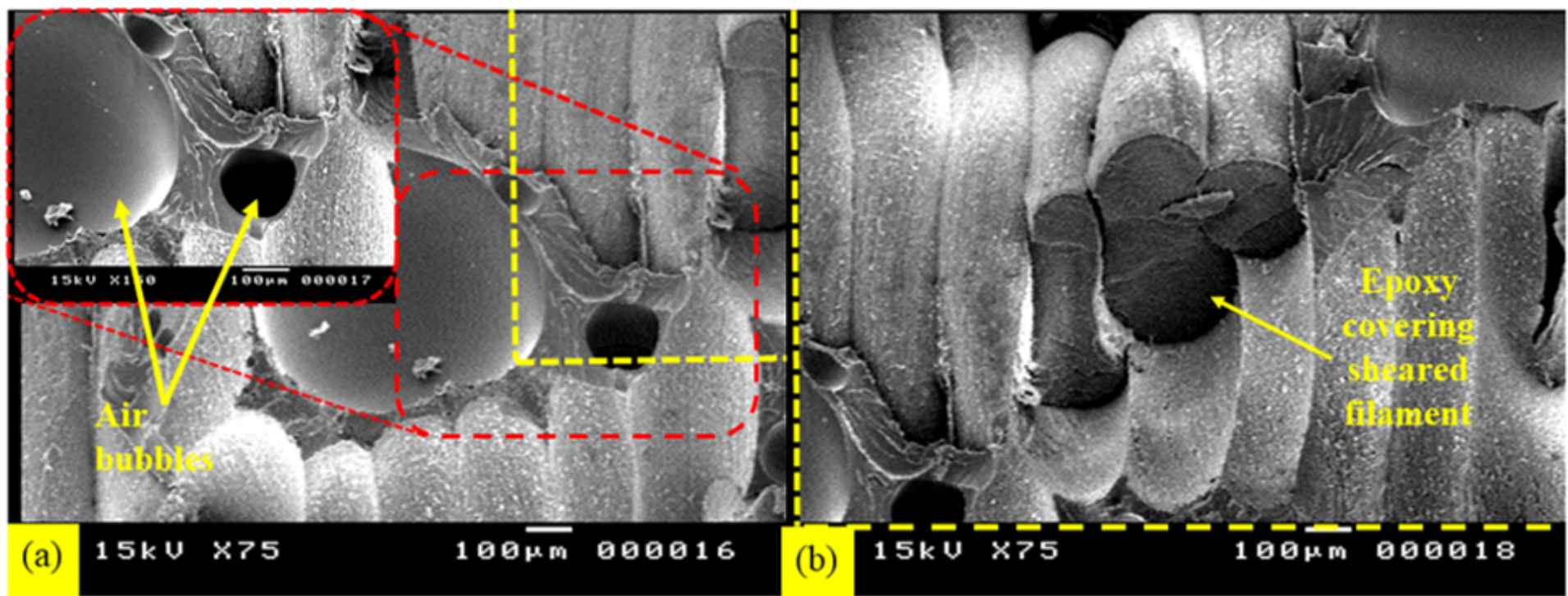


Figure 16

SEM micrographs (60B-40E) 